\title{
Naufragio y rescate de la flota y armada del marqués del Vado del Maestre, 1691
}

\author{
Shipwreck and Rescue of the Fleet and Armada \\ of the Marquis of the Vado del Maestre, 1691
}

\author{
Vicente Pajuelo Moreno \\ ORCID iD: http://orcid.org/0000-0002-1873-1421 \\ Universidad de Cádiz/Universidad de Lisboa
}

Mediante el análisis de las embarcaciones que integraban la flota y armada del general Diego de Córdoba Lasso de la Vega, marqués del Vado del Maestre, se vislumbra el complejo entramado de la marina que se dirigía a Tierra Firme a finales del siglo XVII, la calidad de las naves que transportaban los caudales a la península Ibérica y la existencia de un sistema protocolario en caso de producirse un siniestro. La pérdida de alguno de los navios que transportaban los metales preciosos agravaría aún más los problemas de la resentida Hacienda castellana, por lo que la Corona debía ejecutar un plan de búsqueda y rescate con la mayor celeridad posible para tratar de obtener los valiosos cargamentos.

Palabras ClaVe: Diego de Córdoba Lasso de la Vega; Marqués del Vado del Maestre; Naufragio; Flota; Armada.

The complex structure of the navy that was heading of Tierra Firme of the late seventeenth century is evident trough the analysis of the ships from the fleet and armada of General Diego de Córdoba Lasso de la Vega, Marquis of the Vado del Maestre, the quality of the ships that made the transport of flows to the Iberian Peninsula, life on board and the existence of a protocol system in the event of an incident. The loss of any of the ships that transported precious metals to Spain would aggravate even more the problems to the Castilian treasury. Should it occur, the Crown would have to promptly execute a plan of search and rescue in order to obtain valuable cargos.

Keywords: Diego de Córdoba Lasso de la Vega; Marquis of the Vado del Maestre; Shipwreck; Fleet; Armada.

Copyright: (C) 2019 CSIC. Este es un artículo de acceso abierto distribuido bajo los términos de la licencia de uso y distribución Creative Commons Reconocimiento 4.0 Internacional (CC BY 4.0). 


\section{Introducción}

Tras el desastre naval sufrido por la marina española en la batalla de las Dunas (1639), en la que perdieron la vida un buen número de hombres y prácticamente desapareció la armada, ${ }^{1}$ la Corona centró su atención en proteger el tráfico marítimo mercantil indiano. ${ }^{2}$ Así, a partir de 1647, la Armada de la Guarda se encargó de custodiar siempre a la Flota de Tierra Firme, «unificándose el mando de esta flota y de su escolta en las mismas personas del general y almirante de la Armada de la Avería», ${ }^{3}$ tal y como se observa entre 1690 y 1691 en el convoy comandado por el general Diego de Córdoba Lasso de la Vega. ${ }^{4}$ Con ello se pretendía, entre otras cosas, que en la navegación trasatlántica se procediese con la mayor seguridad posible, aunque entre 1650 y 1700 solo se despacharon dieciocho flotas a Tierra Firme, dos en la última década, prueba inequívoca de que la ruta por la que habían llegado a la metrópoli las mayores cantidades de plata estaba prácticamente muerta a finales de la centuria. ${ }^{5}$

El citado general venía desempeñando la función de máximo dignatario de las flotas y armadas desde 1678, cuando fue elegido general de la Flota de Nueva España. ${ }^{6}$ Un año más tarde fue nombrado general de la Armada de la Guarda de la Carrera de Indias, probablemente a consecuencia del préstamo de 80.000 pesos que había hecho a la Real Hacienda. ${ }^{7}$ En 1693 fue nombrado gobernador de La Habana por cinco años, con un sueldo anual de 14.000 escudos de plata, ${ }^{8}$ aunque no tomó posesión hasta 1695 —año en el que recibió el título de capitán general de Cuba—, debido a las constantes quejas mostradas por el Consejo de Indias y la Junta de Guerra

\footnotetext{
1 Fernández Duro, 1898, t. IV, 205-257.

2 Haring, 1979, 268.
}

3 Joseph de Veitia Linage, Norte de la Contratación de las Indias Occidentales (Sevilla, 1672, lib. II, cap. I, 11), citado en Pérez-Mallaína, 2007, 288. La Armada de la Guarda recibió diferentes denominaciones durante su existencia, una de ellas fue la de «Armada de la Avería», por estar sufragada por el derecho de la avería. Sobre esto último véase Céspedes, 1945, 517-548.

4 Relación de los navíos de la armada y flota de Tierra Firme. Sevilla, 10 de septiembre de 1691. Archivo General de Indias (AGI), Contratación, 3195.

5 Castillo, 1990, 124-127.

6 Registros de ida de los navíos de la Flota de Nueva España, comandada por el general Diego de Córdoba Lasso de la Vega. Año 1678. AGI, Contratación, 1229-1230.

7 Real cédula a los oficiales reales de Panamá, para que paguen a Diego de Córdoba Lasso de la Vega, provisto general de la Armada de Galeones siguiente a la de Gonzalo Chacón. Madrid, 27 de septiembre de 1680. AGI, Panamá, 240, 1.21, 157r-159r.

8 El rey hace merced del gobierno de La Habana a don Diego de Córdoba Lasso de la Vega. Madrid, 2 de abril de 1693. AGI, Santo Domingo, 113, r. 1, n. 1. 
de Indias. ${ }^{9}$ Según el principal órgano de gobierno, el general no podía ocupar el cargo de gobernador por varios motivos, entre los que destacan que solo había ejercido oficios en el mar y que dicho puesto había recaído en los soldados de mayor crédito y graduación, normalmente entre los maestres de campo y generales de artillería. ${ }^{10}$ Afirmaban, además, que la isla de Cuba era la demarcación más importante del Nuevo Mundo, por donde pasaban las flotas y armadas antes de regresar a la península con los caudales del rey y particulares, por lo que dicho puesto era demasiado importante para su persona, a pesar de que eran sabedores de su excelente hoja de servicios como marino.

Diego de Córdoba comenzó a servir como soldado de la Armada de la Guarda en 1675, posteriormente como capitán de infantería de una de las compañías del Tercio de la misma, aunque solo sería por un año, pues en 1677 recibió la patente de capitán de mar y guerra, y poco después la de gobernador del Tercio de dicha marina; en 1678 fue nombrado general de la Flota de Nueva España y un año más tarde de la Armada de la Guarda de la Carrera de Indias. ${ }^{11}$ Durante sus diecisiete años de servicio en las flotas y armadas de la Carrera de Indias, entre 1675 y 1691, frecuentó la navegación trasatlántica como general en cuatro ocasiones..$^{12}$ Cabe señalar también que Diego de Córdoba era caballero de la Orden de Alcántara, ${ }^{13}$ primer marqués del Vado del Maestre,$^{14}$ general de artillería, capitán general del Nuevo Reino de Granada y presidente de la Audiencia de Santa Fe de Bogotá, ejerciendo estos dos últimos cargos desde el 25 de junio de 1703 hasta el 4 de febrero de $1712 .{ }^{15}$

9 Nombramiento de Diego de Córdoba como capitán general de Cuba. AGI, Contratación, 5456, n. 3, r. 23.

10 Véase, por ejemplo, el expediente de información y licencia de pasajero a Indias de Diego Antonio Viana Hinojosa. Sevilla, 12 de mayo de 1687. AGI, Contratación, 5448, n. 7.

11 Real cédula al general de la Armada de las Indias. Madrid, 24 de junio de 1689. AGI, Indiferente, $431,1.43,126 \mathrm{r}-126 \mathrm{v}$.

12 Pérez-Mallaína, 2007, 307.

13 Pruebas para la concesión del título de Caballero de la Orden de Alcántara a Diego de Córdoba Lasso de la Vega y Martínez de Francia Figueroa y Almonte. 20 de marzo de 1656. Archivo Histórico Nacional (AHN), Consejo de Órdenes, Caballeros de la Orden Militar de Alcántara, exp. 373.

14 Asiento de decreto de gracia a nombre de don Diego de Córdoba Lasso de la Vega, sobre merced de título de marqués del Vado del Maestre. Año 1683. AHN, Consejos, 1. 2752, c. 1683, n. 60. El título de marqués del Vado del Maestre fue declarado por el rey como título de carácter imperecedero.

15 Residencia de Diego de Córdoba Lasso de la Vega, gobernador y capitán general del Nuevo Reino de Granada y presidente de la Audiencia de Santa Fe, por Francisco de Meneses Bravo de Sarabia, su sucesor. 9 piezas. Año 1708. AGI, Escribanía, 793C. 


\section{Armada de la Guarda de la Carrera de Indias (1690-1691)}

El número de navíos que integraban la Armada de la Guarda entre 1690 y 1691 fue muy similar al de las armadas que se habían organizado durante todo el siglo XVII, constituidas, normalmente, por entre seis y ocho galeones y entre dos y cuatro pataches. Desde la publicación en 1591 del primer asiento de la Armada de la Guarda, en el que se recogen las primeras condiciones que debía reunir dicha marina, la formación estaría integrada por diez galeones, dos pataches y cuatro lanchas, y su misión principal sería acompañar y asegurar el viaje que, desde las Indias, realizaran la Flota de Tierra Firme y la Flota de Nueva España. ${ }^{16}$ No obstante, la circunstancia de escoltar a ambas flotas se dio en contadas ocasiones hasta 1647, año en el que la Armada de la Guarda empezó a escoltar siempre a la Flota de Tierra Firme, y su objetivo principal fue, desde sus inicios, transportar los metales preciosos entre las colonias americanas y la metrópoli. Según los registros realizados a cada uno de los galeones que constituían la Armada de la Guarda dirigida por Diego de Córdoba, esta estaba formada por siete galeones y cuatro pataches.

La mayor parte de tales embarcaciones habían completado un único viaje redondo - travesía de ida hacia las Indias y travesía de vuelta a la metrópoli-, como era el caso de los galeones San José, capitana del convoy, la almiranta Jesús, María y José, que había sido la capitana de la armada de Gonzalo Chacón entre 1684 y 1686, el galeón nombrado Nuestra Señora del Mar, San José y San Francisco de Paula, ${ }^{17}$ y el Nuestra Señora de la Concepción, San Francisco Javier y San Pedro, que en la citada expedición fue de «gobierno», denominado así porque en él iba embarcado el gobernador del Tercio. ${ }^{18}$ El resto de los galeones habían sido carenados en 1690 por primera vez, a saber: el Nuestra Señora de los Remedios, San Nicolás y San Ignacio, el nombrado Santísimo Sacramento y el buque Nuestra Señora del Rosario y San José, que cumplía ese año las funciones de galeón gobierno. ${ }^{19}$

A finales de siglo, los galeones de la armada solían arquear más de mil toneladas, como era el caso de la capitana, de 1.017 toneladas. La almiranta,

16 Asiento de la Armada de la Guarda. Sevilla, 1 de diciembre de 1591. AGI, Indiferente, 2661.

17 Registro de ida del navío Nuestra Señora del Mar. Sevilla, 7 de septiembre de 1684. AGI, Contratación, 1241, n. 1, r. 12.

18 Registro de ida del navío Nuestra Señora de la Concepción y San Francisco Javier. Sevilla, 16 de febrero de 1690. AGI, Contratación, 1246, n. 9.

19 Registros de ida a Tierra Firme de los galeones del general Gonzalo Chacón Medina y Salazar. Cádiz, 22 de septiembre de 1684. AGI, Contratación, 1241, n. 1, r. 2, 3, 8, 10 y 12. 
de dimensiones más reducidas, casi alcanzaba el millar con sus 965 7/8 toneladas. Ambos habían sido construidos, probablemente, al igual que el resto de los que integraban la armada, en los astilleros peninsulares del Cantábrico, ${ }^{20} \mathrm{y}$, a excepción del galeón de Ignacio de Ubilla, de 561 toneladas, ${ }^{21}$ todos podían portar más de 850 toneladas. El galeón nombrado Nuestra Señora de las Mercedes, San Francisco Javier y San Miguel se construyó por asiento signado entre la Corona y Francisco de Córdoba Lasso de la Vega, hijo del general, en 1688, lo que le valió para recibir el título de capitán de mar y guerra. Dicho galeón aparece referido en las fuentes, en más de una ocasión, con el término «patache», debido a que esta solía ser la tipología naval empleada para cumplir la misión de ir a recoger las perlas que se obtenían, principalmente, en aguas cercanas a la isla Margarita, cuyo cometido había sido encomendado a Francisco de Córdoba. ${ }^{22}$ Entre las condiciones del citado acuerdo constaba la obligación por parte del capitán de correr con todos los gastos ordinarios de la fábrica del navío, además de transportarlo hasta Andalucía y proporcionar un préstamo al $8 \%$ para financiar los fletes. Por su parte, este recibía licencia para realizar dos viajes consecutivos, en los que podía comerciar y percibir elevadas cantidades por la carga transportada, ${ }^{23}$ tal y como fue el caso del gobernador conde de Gerena, quien ya había fabricado un galeón de 800 toneladas para el viaje en el que sirvió al lado del general Gonzalo Chacón. Para la empresa de 1690 tenía confeccionado otro galeón de 928 toneladas, nombrado Nuestra Señora del Rosario y San José, que, a razón de 20 ducados la tonelada, suponía su construcción un total de 18.562 ducados y medio. Dicho galeón ya había servido como almiranta en la armada de Gonzalo Chacón, entre 1684 y 1686, y pasó a ser el galeón gobierno de la armada en $1690 .{ }^{24}$ Análoga situación se observa con los capitanes Francisco de Pineda y Salinas — que fue el almirante de la

20 Serrano Mangas, 1998.

21 Registro de ida del navío Nuestra Señora de los Remedios. Cádiz, 27 de febrero de 1690. AGI, Contratación, 1247, n. 9.

22 Navarrete Peláez, 2003.

23 Real cédula a los oficiales reales de Panamá para que paguen al capitán Francisco de Córdoba Lasso de la Vega ocho mil pesos para concluir y transportar su bajel. Madrid, 5 de octubre de 1688. AGI, Panamá, 241, 1. 23, 3v-5r. En ella el rey dispone lo siguiente: «se le libren 8.000 pesos, que oy son escudos de a 10 reales de plata [...] para que valiendose de este credito pueda adelantar la fabrica de su galeon y transportarle a la Andaluzia», lo cual denota las diferentes reformas monetarias que se habían realizado últimamente. Véase, en este sentido, Font de Villanueva, 2005.

24 Real cédula a los oficiales reales de Panamá para que paguen al conde de Gerena, provisto gobernador del Tercio de Galeones para dos flotas, en atención a los méritos de su padre Pedro de Ursúa y al ofrecimiento que ha hecho de fabricar un galeón de 800 toneladas y prestar 40.000 pesos, más sus intereses (el $8 \%$ ). Aranjuez, 4 de mayo de 1687. AGI, Panamá, 240, 307v-310v. 
armada comandada por el referido general—, Ignacio de Ubilla —que venía participando en las armadas como capitán de mar y guerra desde el año 1667-,${ }^{25}$ Juan de Egues Beaumont y Pedro Adrián Colarte.

El procedimiento habitual seguido por el monarca para paliar la falta de galeones a finales de la centuria fue el de otorgar el puesto de capitán de mar y guerra a quienes se comprometían a construir uno de ellos. La Corona únicamente debía proporcionar la artillería y el carenado. ${ }^{26}$ En las tablas 1 y 2 incluimos el nombre de los galeones, pataches y capitanes de la Armada de la Guarda de la Carrera de Indias, así como el tonelaje de cada uno de los galeones.

TABLA 1

GALEONES DE LA ARMADA DE LA GUARDA DE LA CARRERA DE INDIAS (1690-1691)

\begin{tabular}{|c|c|c|}
\hline Galeón & Capitán & Toneladas \\
\hline San José (capitana) & $\begin{array}{l}\text { Diego de Córdoba Lasso de la } \\
\text { Vega (general), Juan de Córdoba } \\
\text { Lasso de la Vega (capitán) }\end{array}$ & 1.017 \\
\hline Jesús, María y José (almiranta) & $\begin{array}{l}\text { Pedro Carillo de Albornoz } \\
\text { (almirante), Marcos de } \\
\text { Consuegra (capitán) }\end{array}$ & $9657 / 8$ \\
\hline $\begin{array}{l}\text { Nuestra Señora del Rosario } \\
\text { y San José (gobierno) }\end{array}$ & $\begin{array}{l}\text { El conde de Gerena, gobernador } \\
\text { del Tercio }\end{array}$ & $9287 / 8$ \\
\hline $\begin{array}{l}\text { Nuestra Señora de los Remedios, } \\
\text { San Nicolás y San Ignacio }\end{array}$ & Ignacio de Ubilla & $5611 / 8$ \\
\hline $\begin{array}{l}\text { Nuestra Señora del Mar, San José } \\
\text { y San Francisco de Paula }\end{array}$ & Francisco de Pineda y Salinas & $8521 / 8$ \\
\hline El Santísimo Sacramento & Juan de Egues Beaumont & $8651 / 4$ \\
\hline $\begin{array}{l}\text { Nuestra Señora de la Concepción, } \\
\text { San Francisco Javier y San Pedro }\end{array}$ & Pedro Adrián Colarte & $8821 / 4$ \\
\hline
\end{tabular}

Fuente: AGI, Contratación, 1246-1248, 3195, 5453 n.171. AGI, Panamá, 240, 1. 22, 241, 1. 23-24.

25 Real cédula a los oficiales reales de Panamá para que paguen a Ignacio de Ubilla, capitán de mar y guerra que ha de ir en la Armada de Tierra Firme, 18.000 pesos que ha prestado a la Real Hacienda, más sus intereses (el $8 \%$ ). Madrid, 1 de enero de 1667. AGI, Panamá, 239, 1.19, 206v-208v. 26 Serrano Mangas, 1998. 
TABLA 2

PATACHES DE LA ARMADA DE LA GUARDA DE LA CARRERA DE INDIAS (1690-1691)

\begin{tabular}{|l|l|}
\hline \multicolumn{1}{|c|}{ Patache } & \multicolumn{1}{c|}{ Capitán } \\
\hline $\begin{array}{l}\text { Galeón patache de La Margarita, } \\
\text { Nuestra Señora de las Mercedes, } \\
\text { San Francisco Javier y San Miguel }\end{array}$ & Francisco de Córdoba Lasso de la Vega \\
\hline Patache Nuestra Señora de la Estrella & Domingo de Zabalburu \\
\hline $\begin{array}{l}\text { Santo Cristo de las Penas y Nuestra } \\
\text { Señora del Pópulo (patache de } \\
\text { Portobelo) }\end{array}$ & Lorenzo Tello (cabo de infantería) \\
\hline $\begin{array}{l}\text { Nuestra Señora del Pópulo y el Águila } \\
\text { (patache de Cuba) }\end{array}$ & $\begin{array}{l}\text { José López de Carvajal (cabo de } \\
\text { infantería) }\end{array}$ \\
\hline
\end{tabular}

Fuente: AGI, Contratación, 1246-1248, 3195, 5453 n.171. AGI, Panamá, 240, 1. 22, 241, 1. 23-24.

El 14 de marzo de 1690 pusieron rumbo a Cartagena los navíos que formaban parte de la flota y armada del general Diego de Córdoba y del almirante Pedro Carrillo de Albornoz. ${ }^{27}$ A su despacho asistieron los señores Juan de Chaves y Chacón, presidente de la Casa de la Contratación, y don Francisco Lorenzo de San Millán, juez oficial de la Real Audiencia de la Casa de la Contratación. ${ }^{28}$ En poco más de un mes de navegación, los barcos que integraban el convoy se hallaban muy cerca de las Antillas menores ${ }^{29}$ y a comienzos de mayo arribaron a Cartagena. ${ }^{30}$ Entre los días 7 y 15 de dicho mes se realizaron los correspondientes pregones en aquella

27 Real cédula a los oficiales reales de Panamá para que paguen a Pedro Carrillo de Albornoz, provisto almirante de la armada que ha de ir a Tierra Firme del cargo del marqués del Vado del Maestre, 19.302 ducados y medio de plata, que ha de haber por la carena de la almiranta. Madrid, 10 de octubre de 1688. AGI, Panamá, 241, 1. 23, 15r-18r. El nombramiento del almirante Carrillo de Albornoz se realizó por decreto real el 31 de enero de 1687, probablemente a consecuencia del préstamo que había concedido a la Corona para el carenado de la almiranta.

28 Relación de los navíos de la Armada y Flota de Tierra Firme, s/1 y s/a (probablemente 1690). AGI, Contratación, 3195.

29 Carta de Diego de Córdoba al rey. En el galeón San José, 22 de abril de 1690. AGI, Contratación, 625. Alonso García Pimpollo, que era el piloto principal de la capitana, realizó averiguaciones ese mismo día sobre la posición y altura de cada uno de los navíos, lanzando una pieza de leva y colocando una bandera en la jarcia de gavia para que las embarcaciones acudiesen al lugar donde se hallaba el galeón capitana y diesen su posición en la que estaban previo aviso del piloto.

30 Aviso de la llegada de la armada. En el galeón San José, 4 de mayo de 1690. AGI, Contratación, 625. 
ciudad con el fin de comprobar si alguna persona podría aportar los bastimentos necesarios para la estadía y el viaje de vuelta, sin embargo nadie acudió a la llamada. ${ }^{31}$ La situación se tornaría aún más complicada para el general a mediados del mes siguiente, pues, estando surtos los galeones en el amarradero del puerto de Cartagena, una tormenta causó graves daños a las embarcaciones, especialmente en la arboladura. Los maestros mayores y calafates trabajaron en ellos durante el verano de 1690, respetando la jerarquía de las naves: primero sería reparado el galeón capitana, posteriormente la almiranta, le seguiría el galeón gobierno y así sucesivamente hasta finalizar con las naos mercantes. ${ }^{32}$

Una vez enmendados los principales daños que les había causado la tormenta, tocaba emprender el viaje hacia Portobelo, en donde, en aquella ocasión, fueron carenados para el viaje de vuelta. Debido a la presencia de dos buques holandeses en Nombre de Dios, el general convocó una junta de capitanía general e hizo llamar al almirante y a los capitanes para que diesen su opinión sobre el asunto. ${ }^{33} \mathrm{La}$ acción de reunir a los principales mandos de la armada se ha observado también otros años, como por ejemplo en 1597, cuando el general Juan Gutiérrez de Garibay citó a sus principales subordinados para que acudiesen a la capitana, aunque las causas que motivaron cada una de las juntas fueron bien distintas. ${ }^{34} \mathrm{El}$ general Diego de Córdoba vio los votos de los capitanes y manifestó, coincidiendo con la mayoría, que se enviarían dos barcos para expulsar a los navíos holandeses de Nombre de Dios. A los capitanes elegidos para la ocasión, don Francisco de Pineda y don Juan de Egues, les correspondía poner a punto sus galeones; sin embargo, finalmente solo se despachó una lancha al amanecer, en la que iría Luis de Arana, ayudante de Diego de Córdoba, para entregarles una carta y conocer cuáles eran sus intenciones. La lancha regresó por la noche con la respuesta que le dieron los capitanes, en idioma holandés, por

31 Auto y pregones que se dieron trayendo en pregón los bastimentos para el abasto de esta armada. Cartagena, 15 de mayo de 1690. AGI, Contratación, 3196.

32 Cuaderno de señalamiento de obra de los galeones y naos mercantes. Cartagena, 12 de junio de 1690. AGI, Contratación, 3196.

33 Juntas de capitanía general prohibiendo el tráfico con los navíos extranjeros que están en Nombre de Dios y que se les escriba papel para que desalojen aquel paraje. Portobelo, 1 de diciembre de 1690. AGI, Contratación, 625.

34 Pérez-Mallaína, 2010, 319-344. El general Juan Gutiérrez de Garibay, ante el acoso de velas enemigas en su viaje de regreso a las costas andaluzas, decidió desembarcar en la fortaleza de Angra, isla Tercera, los metales preciosos que transportaban los galeones; en cuanto Garibay vio la ocasión de escapar de allí, puso rumbo a Sanlúcar, adonde arribó en febrero de 1598 con toda la hacienda obtenida en las Indias. 
lo que se pidió a los diputados del comercio que la tradujeran. La cuestión principal que revelaba la misiva era que entre ambas potencias se seguían conservando los acuerdos de paz existentes y que en breve partirían por el canal de Bahamas hacia Holanda. ${ }^{35}$

\section{Flota de Tierra Firme y navíos de costa}

En 1690, además de los galeones y pataches que integraban la Armada de la Guarda de la Carrera de Indias, un total de quince navíos constituían la Flota de Tierra Firme que les acompañaba. Las dimensiones de los mismos eran más reducidas que la de los galeones, puesto que las medidas del barco más grande de la flota apenas rebasaban el porte del navío de menor tamaño de la armada. La protección que ofrecían los galeones para realizar la travesía que les conducía primero a Cartagena y posteriormente a Portobelo, lugar este último en donde se recogían los metales procedentes, principalmente, de las minas de Potosí, ${ }^{36}$ infundían mayor seguridad a las embarcaciones que deseaban realizar la navegación hacia el Nuevo Mundo. Por ello, el número de bajeles que aguardaban la partida de la armada fue en constante aumento durante todo el siglo XVII. La lógica respondía al mayor número de piezas de artillería que montaban los galeones, mejor pertrechados que los navíos de las diferentes flotas que cruzaron el Atlántico y con capacidades defensivas superiores. ${ }^{37}$

La construcción de los bajeles que formaban la flota se había realizado casi en su totalidad en los astilleros del País Vasco, centro predominante para la confección de navíos de alto bordo. ${ }^{38}$ A medida que transcurría el siglo XVII, se fueron incorporando embarcaciones fabricadas en diferentes partes de las Indias, sin embargo la representación de navíos construidos en la península ocupó un lugar predominante durante toda la centuria. La calidad de la madera que ofrecían los bosques indianos superaba incluso a la obtenida en la cornisa cántabra. No obstante, América carecía en esos momentos de los materiales necesarios para obrarlos, tales como el hierro, la estopa, la jarcia, etc., y transportarlos desde la península encarecería los

35 Carta del general Diego de Córdoba a los navíos holandeses. Portobelo, 3 de diciembre de 1690. AGI, Contratación, 625.

36 Pérez-Mallaína y Torres Ramírez, 1987, 1-17. Estos metales llegaban a Portobelo gracias a la Armada del Mar del Sur.

37 Serrano Mangas, 1992, 11-24.

38 Odriozola Oyarbide, 2002. 
costes de la construcción. En la tabla 3 mostramos los nombres de los diferentes barcos que integraban la Flota de Tierra Firme en 1690 y de los maestres de plata, ${ }^{39}$ así como el lugar donde fueron construidos los bajeles y el porte de cada uno de ellos.

TABLA 3

FLOTA DE TIERRA FIRME (1690-1691)

\begin{tabular}{|l|l|l|c|}
\hline \multicolumn{1}{|c|}{ Barco } & \multicolumn{1}{|c|}{ Maestre } & $\begin{array}{c}\text { Lugar de } \\
\text { construcción }\end{array}$ & Toneladas \\
\hline $\begin{array}{l}\text { Santo Cristo de } \\
\text { San Agustín }\end{array}$ & Bartolomé de Aperribay & Vizcaya & 448 1/4 \\
\hline $\begin{array}{l}\text { Nuestra Señora de Regla, } \\
\text { San José y San Ignacio }\end{array}$ & Francisco de Ellauri & Vizcaya & 507 3/8 \\
\hline $\begin{array}{l}\text { Nuestra Señora de la } \\
\text { Estrella y San Lorenzo }\end{array}$ & Laureano Jiménez & Vizcaya & 589 3/8 \\
\hline $\begin{array}{l}\text { Santo Cristo de } \\
\text { San Román y Nuestra } \\
\text { Señora de Copacabana }\end{array}$ & Martín de Zabala & Campeche & 348 \\
\hline El Ángel y las Ánimas & Isidro de Arrevillaga & Vizcaya & 263 1/2 \\
\hline $\begin{array}{l}\text { Nuestra Señora de la } \\
\text { Concepción, San José } \\
\text { y las Ánimas }\end{array}$ & Ignacio de los Cameros & Vizcaya & 357 \\
\hline Nuestra Señora de Atocha & Juan Fernández de Ulloa & Vizcaya & 564 1/8 \\
\hline $\begin{array}{l}\text { Nuestra Señora de los } \\
\text { Remedios y las Ánimas }\end{array}$ & Diego Rosales Vallejo & Vizcaya & 283 \\
\hline $\begin{array}{l}\text { Nuestra Señora del } \\
\text { Carmen y San José }\end{array}$ & Diego Ibáñez de Guevara & Campeche & 241 4/5 \\
\hline $\begin{array}{l}\text { Nuestra Señora de la } \\
\text { Victoria y San Francisco } \\
\text { de Paula }\end{array}$ & Melchor Castaño & Vizcaya & 373 \\
\hline
\end{tabular}

Fuente: AGI, Contratación, 1246-1248, 3195, 5453 n.171. AGI, Panamá, 240, 1. 22, 241, 1. 23-24.

39 En las embarcaciones iban dos maestres, el de la plata y el de raciones. El primero era el principal responsable de supervisar que «el barco dispusiese de todos los medios materiales y humanos necesarios para llegar a su destino y encargarse de que el pasaje y la carga se entregasen en perfectas condiciones», mientras que el segundo era el encargado de velar por los bastimentos de que disponía la tripulación. Véase Pérez-Mallaína, 1992, 93-97. 
Igualmente realizaban la navegación desde Cádiz un total de cinco navíos de costa, denominados así porque su destino no sería ni Cartagena ni Portobelo, sino diferentes puntos de la costa caribeña. En la tabla 4 se cita el lugar donde fueron fabricados, así como el nombre del maestre, el tonelaje de cada uno de ellos y su destino.

\section{TABLA 4}

NAVÍOS DE COSTA

\begin{tabular}{|c|c|c|c|c|}
\hline Barco & Maestre & Construcción & Toneladas & Destino \\
\hline Jesús Nazareno & $\begin{array}{l}\text { Manuel José } \\
\text { de León }\end{array}$ & Indias & $3913 / 8$ & La Habana \\
\hline Santa María & $\begin{array}{l}\text { Pascual de } \\
\text { Iriarte }\end{array}$ & Hamburgo & $2253 / 4$ & Campeche \\
\hline $\begin{array}{l}\text { Jesús Nazareno, } \\
\text { N. }{ }^{a} \text { S. }{ }^{\text {a del Carmen }} \\
\text { y San Fernando }\end{array}$ & \begin{tabular}{|l} 
Pedro \\
Fernández de \\
Valenzuela
\end{tabular} & Indias & 220 & $\begin{array}{l}\text { Isla } \\
\text { Trinidad }\end{array}$ \\
\hline $\begin{array}{l}\text { N. }{ }^{\text {a }} \text { S. a del Carmen, } \\
\text { San Diego y las Ánimas }\end{array}$ & \begin{tabular}{|l|} 
Francisco \\
Sánchez Durán
\end{tabular} & Triana & 106 & $\begin{array}{l}\text { Santa } \\
\text { Marta }\end{array}$ \\
\hline $\begin{array}{l}\text { Santo Cristo de San } \\
\text { Agustín, N. }{ }^{\text {a }} \text { S. }{ }^{\text {a de la }} \\
\text { Soledad y San Laureano }\end{array}$ & $\begin{array}{l}\text { Juan Luis } \\
\text { García } \\
\text { Villalobos }\end{array}$ & Triana & $99 \frac{1 / 2}{2}$ & Maracaibo \\
\hline
\end{tabular}

Fuente: AGI, Contratación, 1246-1248, 3195, 5453 n.171.

\section{Naufragio y rescate}

A finales de marzo de 1691, continuaban apostados en Portobelo los galeones y los navíos de la Flota de Tierra Firme. Fueron varias las causas que motivaron que el general Diego de Córdoba permaneciese en aquel puerto y retrasase su salida: la primera, la celebración de una feria, en donde la mayor parte de la tripulación tenía puestos sus intereses $;{ }^{40}$ la segunda, la ausencia de tiempos bonancibles para poder partir; y la tercera y más importante, el no haber arribado aún la plata de Potosí. ${ }^{41}$

40 Vila Vilar, 1982.

41 Carta del general Diego de Córdoba Lasso de la Vega, informando del estado de la armada. A bordo del San José, galeón capitana, Portobelo, 19 de febrero de 1691. AGI, Contratación, 625. 
La salida del convoy desde Portobelo en dirección a Cartagena no se produjo hasta mediados de abril de 1691. La parada que había de realizarse antes de emprender el viaje de vuelta hacia Cádiz para la recogida de bastimentos y reparación de alguno de los navíos que mostrasen algún defecto se prolongó más de lo debido, ya que varios barcos hacían demasiada agua y hubo que efectuar numerosas reparaciones..$^{42} \mathrm{~A}$ finales de mayo, las embarcaciones que integraban la Armada de la Guarda y la Flota de Tierra Firme levaron anclas para dirigirse a La Habana, pero apenas transcurridos unos días de navegación, un accidente provocó que cuatro de las embarcaciones se perdieran para siempre en el bajo de Las Víboras, conocido actualmente como Pedro Bank, situado a unos ochenta kilómetros al suroeste de Jamaica (figura 1).

No era la primera vez que aquellos bajos se convertían en escenario de un desastre, pues en 1605 la armada del general Luis Fernández de Córdoba y Sotomayor también se topó con ellos durante una fuerte tormenta, que ocasionó el naufragio de cuatro de las embarcaciones de su conserva. ${ }^{43}$ No obstante, las causas que provocaron uno y otro son bien distintas. Los cuatro navíos que naufragaron en el bajo de Las Víboras la noche del 2 de junio de 1691 no padecieron ningún fenómeno meteorológico adverso, sino que no habían sido bien remendados y eran los más viejos de la formación. Así, uno de esos cuatro navíos, el nombrado Nuestra Señora de la Concepción, San José y las Ánimas, que efectuó su primer viaje en 1682 en conserva de la Flota de Nueva España, ${ }^{44}$ al igual que otro de los que naufragaron, el Ángel y las Ánimas, ${ }^{45}$ venían atravesando el Atlántico con periodicidad casi anual desde aquel año; aunque verdaderamente llamativo fue el caso del navío Nuestra Señora del Carmen y San José, que se hizo a la vela por primera vez en $1672,{ }^{46}$ lo que

42 Reparaciones realizadas a los galeones y pataches de la armada desde el día 1 de mayo hasta el día 27 del mismo mes. Cartagena, 27 de mayo de 1691. AGI, Contratación, 3196. Se repararon el galeón Nuestra Señora del Mar, el galeón Nuestra Señora de las Mercedes y el patache Nuestra Señora de la Estrella. Pedro Sánchez, maestro mayor de calafate del galeón capitana, afirma: «era normal que entrara agua por la flaqueza y antigüedad de las carenas y que con las planchadas que se le pusieron está seguro podrá hacer viaje a España».

43 Segovia Salas, 2007.

44 Registro de ida del navío Nuestra Señora de la Concepción, San José y las Ánimas, de 357 toneladas, maestre Juan Ignacio de Cárdenas, que salió de Cádiz con la Flota de Diego Fernández de Zaldívar para Nueva España. En la Casa de la Contratación, 13 de mayo de 1682. AGI, Contratación, 1238, n. 8.

45 Registro de ida del navío El Ángel y las Ánimas, de doscientas sesenta y tres toneladas, maestre Isidro de Arrevillaga, que salió del río Guadalquivir, con la Flota de Diego Fernández de Zaldívar, para Nueva España. En la Casa de la Contratación, 23 de abril de 1682. AGI, Contratación, 1239, n. 4.

46 Registro de ida del navío Nuestra Señora del Carmen y San José, maestre Juan Pérez Núñez, que salió del río Guadalquivir con la Flota de Diego de Ibarra para Tierra Firme. En la Casa de la Contratación, 4 de septiembre de 1671. AGI, Contratación, 1219, n. 8. 


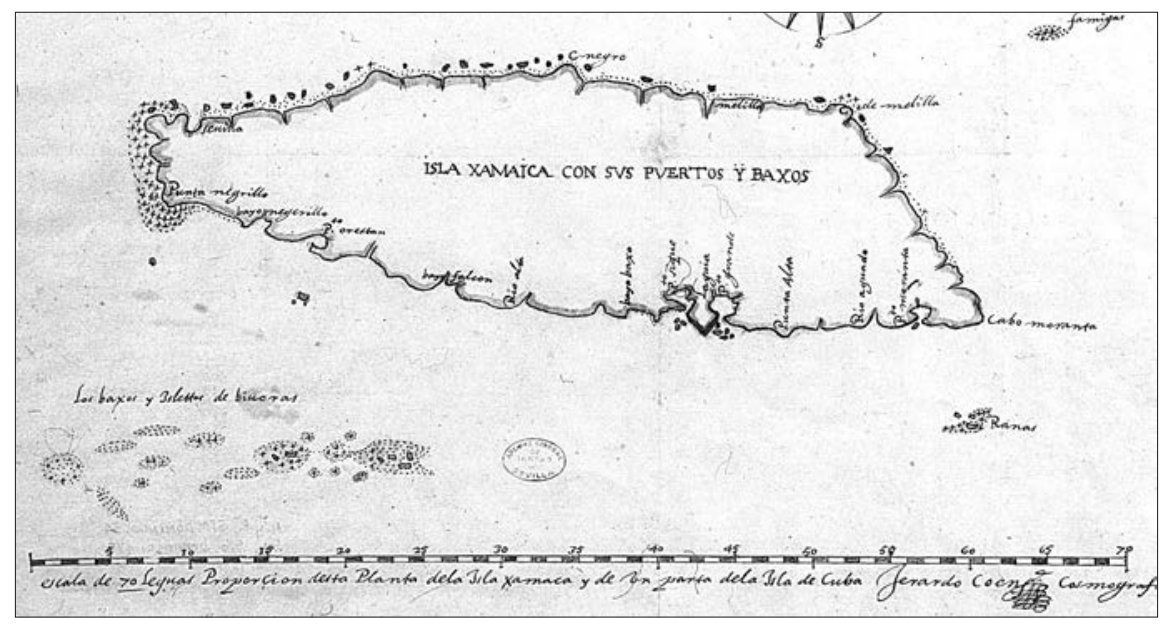

FIgURA 1. Mapa de la Isla Jamaica con sus puertos y bajos (detalle). AGI, Mapas y Planos, Santo Domingo, 54.

significaría que, de haber arribado con el resto de embarcaciones al puerto gaditano, habría servido veinte años en las escuadras españolas. Este hecho sería una excepción, pues si comparamos la vida útil de ese navío con la duración de la mayoría de las embarcaciones que integraron las flotas y armadas de la Carrera de Indias, no era frecuente que rebasasen más de diez años de travesías trasatlánticas. Los tres barcos citados eran de la conserva de la Flota de Tierra Firme y el otro, nombrado Santa Cruz, Santa Teresa y San Francisco de Paula, era uno de los que constituían la Flota de Nueva España, ${ }^{47}$ pero, por haber arribado a Cartagena en el momento de la partida de la Armada de la Guarda y Flota de Tierra Firme, se había incorporado a la expedición dirigida por el general Diego de Córdoba. Esta embarcación venía realizando la navegación trasatlántica desde 1678, año en que se dirigió por primera vez hacia Tierra Firme bajo las órdenes del general Enrique Enríquez de Guzmán. ${ }^{48}$ También pudo repercutir en la desgracia el hecho de que navegaban de noche en una zona de bajos, bien por la falta de pericia de los pilotos o por el desconocimiento de los mismos de la posición geográfica en la que se encontraban.

47 Registro de ida del navío Santa Cruz y Santa Teresa, maestre Juan López de Dios, que salió con la Flota del conde de Villanueva para Nueva España. En la Casa de la Contratación, 17 de junio de 1689. AGI, Contratación, 1245, n. 2, r. 10.

48 Registro de ida del galeón Santa Cruz y Santa Teresa, almirante Gonzalo Chacón, que salió con la armada del general Enrique Enríquez de Guzmán, capitán general de la Armada de la Guarda de la Carrera de Indias, para Tierra Firme. En Cádiz, 16 de julio de 1678. AGI, Contratación, 1232, n. 7. 
Los navíos que formaban parte del convoy dirigido por el general Diego de Córdoba entraron en La Habana el 7 de julio de 1691. Atrás quedaron perdidos cuatro bajeles de su conserva, ahogándose algunos individuos. Sin embargo, muchas de las personas que venían en ellos lograron salvarse gracias al auxilio ofrecido por el galeón Nuestra Señora de Regla, San José y San Ignacio. El riesgo de que hubiera naufragado un mayor número de embarcaciones lo encontramos en los testimonios que dieron cada uno de los capitanes nada más arribar a La Habana, en los que todos coincidían en que los navíos no habían sido bien reparados ni en Portobelo ni en Cartagena. El galeón patache, del que era capitán don Francisco de Córdoba, y el galeón Nuestra Señora de la Concepción, San Francisco Javier y San Pedro, dirigido por Pedro Adrián Colarte, también habían tocado en el bajo de Las Víboras y tuvieron serias dificultades para alcanzar el puerto cubano. En las labores de reparación y arreglo de los mismos trabajaron Pedro Sánchez y Andrés Maltés, maestros mayores de calafatería y carpintería, respectivamente, y los buzos de los galeones capitana, almiranta y el galeón patache: Miguel Pantoja, Luis Pantoja, Francisco Rodríguez Quevedo y Francisco Hernández..$^{49}$ Ante los daños que mostraban las embarcaciones y la necesidad de rescatar la hacienda naufragada, el general Diego de Córdoba decidió reunir en la casa del gobernador y capitán general de Cuba, Severino de Manzaneda, a las personas con cargos y ocupaciones más importantes de La Habana y a Pedro Carrillo, almirante de la formación. Finalmente, entre todos acordaron que se enviarían tres navíos al bajo de Las Víboras para sacar la plata anegada en el interior de las malogradas embarcaciones. ${ }^{50}$

Los diputados del comercio Rodrigo de Vivero, Pedro de Vidales y Antonio Rodríguez Cortés, quienes también habían participado en la junta de capitanía general, afirmaron que:

Habiendose perdido en el bajo de la vibora los cuatro navios, Santa Cruz, La Concepcion, el Angel y Nuestra Señora del Carmen, que eran de la conserva y cargo de V.S., el dia dos de junio en la noche, y salvandose la gente de ellos, que recogio el navio Nuestra Señora de Regla, se sabe que dichos navios, los tres quedaban enteros, aunque el uno habia padecido un fuego que le consumio las obras muertas que descubrira, y que en todos cuatro quedaban porciones de plata, que, por la calidad del tiempo y la prisa necesaria para poner tanta gente en salvo, no se pudo recoger; y por ser breve y no dar lugar a que los ingleses, por la cercania que tienen de Jamaica, se

49 Señalamiento de las obras hechas en La Habana. En el puerto de la ciudad de San Cristóbal de La Habana a bordo del galeón San José, capitana, 7 de julio de 1691. AGI, Contratación, 3196.

50 Junta de capitanía general. La Habana, 12 de Julio de 1691. AGI, Consulados, 843. 
anticipen y la saquen, recurren a V.S. con el nuevo motivo que les da haber personas que se ofrezcan con embarcaciones, asi de la Trinidad como de este puerto para bucear dichos navios. ${ }^{51}$

Para realizar la inmersión en el bajo de Las Víboras se presentaron tres memoriales, que recogían las condiciones de cada uno de los dueños de las embarcaciones dispuestas a zarpar en busca de la plata. Los términos del contrato exigían al monarca la tercera parte de todo lo rescatado, más el sueldo que debía pagar la Real Hacienda a los dueños de las embarcaciones. Estos quedaban obligados a llevar sus barcos bien artillados, con personal suficiente para su defensa y un buen número de buzos. Ante las pretensiones de quienes se habían ofrecido a proceder a la inmersión, los participantes de la junta organizada por el general acordaron que quienes efectuasen las operaciones de recogida de la plata no obtendrían la tercera parte sino la cuarta y, por el riesgo de los piratas que podían merodear en la zona, no se llevaría la plata al puerto de La Habana sino al de Trinidad, desde donde se transportaría vía terrestre hasta el citado puerto habanero. En cada embarcación irían dos personas al cuidado de todo lo obtenido con el buceo, una de ellas nombrada por el rey, el gobernador y los oficiales reales, y la otra a elección de los diputados del comercio. Por cabo y máximo responsable de los tres navíos fue el capitán Esteban de Berroa, ${ }^{52}$ quien ya había participado en otros buceos como el que se realizó en el canal de las Bahamas en 1679, ${ }^{53}$ concretamente en el paraje de Los Mimbres, donde se perdió en 1656 la almiranta de Matías de Orellana. ${ }^{54}$

Los tres bajeles que se dispusieron para recoger la plata fueron los siguientes: la fragata Nuestra Señora de la Concepción, propiedad del capitán Sebastián de Herrera; la balandra San Pedro y las Ánimas, cuyos dueños eran Manuel Rodríguez y Silvestre Gómez; y la balandra Nuestra Señora del Sagrario y San Francisco Javier, que pertenecía a Cristóbal de Oliver. Esta última se hallaba en el puerto de Trinidad y, según las instrucciones que se les había dado a los veedores de cada una de las embarcaciones, se

51 Idem.

52 Galeones del general marqués del Vado del Maestre. La Habana, 20 de julio de 1691. AGI, Santo Domingo, 463.

53 Capitán Miguel de Melgar. Expediente del asiento para el buceo de la almiranta de galeones de don Matías de Orellana, perdida el año 1656 en el canal de las Bahamas. Año 1656. AGI, Indiferente, 2699, n. 3. Al buceo de la almiranta había asistido el capitán Miguel de Melgar, pero a causa de su fallecimiento, Esteban de Berroa ocupó su puesto.

54 Relación de méritos y servicios de Esteban de Berroa, capitán de mar y guerra, vecino de Cumaná. La Habana, 21 de octubre de 1679. AGI, Indiferente, 127, n. 77. 
incorporaría más tarde al buceo. La orden disponía, además, «que a los indios buzos se les tratase con amor y cariño», pues de esa manera estos podrían descender más en el agua. La práctica de sumergirse a pulmón en el Caribe era muy peligrosa, por ello, en la mayoría de las ocasiones, fueron estos «elegidos» quienes realizaban las inmersiones, y no porque su capacidad pulmonar y sus técnicas fuesen mejores, sino porque la pérdida de uno de estos individuos no sería tan lastimosa como la de un humano de piel blanca, además de que el coste del descenso sería mucho más económico que el practicado por los buzos específicos de la Armada, cuyos sueldos eran muy elevados. ${ }^{55}$

Desde el puerto habanero partieron en dirección al bajo de Las Víboras, el 19 de julio de 1691, la balandra San Pedro y las Ánimas y la fragata Nuestra Señora de la Concepción, denominada también «La Bobona». El 20 de agosto arribaría al mismo punto la balandra Nuestra Señora del Sagrario y San Francisco Javier, que solo ese día pudo obtener algún beneficio, pues las otras dos embarcaciones, como no podía ser de otra forma dado el tiempo transcurrido, ya habían extraído casi toda la plata. ${ }^{56}$

Los descendimientos se produjeron entre los días 8 y 20 de agosto de 1691, aunque debido al mal tiempo no todos los días se pudieron realizar inmersiones. Las tres naves entraron en el puerto de la Trinidad cinco días después de haber realizado el último descenso y, a excepción de los propietarios de la balandra Nuestra Señora del Sagrario y San Francisco Javier, que partieron tarde del puerto de Trinidad y escasamente pudieron participar en el negocio, el resto de los componentes de la empresa recibieron generosos emolumentos. ${ }^{57}$

El monto de lo obtenido en el buceo rondaba los 200.000 pesos, pero de ahí se tenía que pagar el salario a los dueños de las embarcaciones que se ofrecieron a realizar la inmersión, restando lo cual quedaban 164.155 pesos y 7 reales y medio. Los salarios que se pagaron a los dueños de las tres embarcaciones fueron los siguientes: a Manuel Rodríguez y Silvestre Gómez, dueños de la balandra San Pedro, 23.211 pesos y 3 reales; a Sebastián de

55 Serrano Mangas, 1991, 107-118.

56 Diario del viaje que se hace al bajo de La Víbora, en donde están perdidos la nao Santa Cruz, La Concepción, el Ângel y las Ánimas y Campechano (el sobrenombre de Campechano le venía dado porque había sido fabricado en Campeche), de la conserva de los galeones del marqués del Vado del Maestre, de orden del señor maestre de campo don Severino de Manzaneda y Salinas, gobernador y capitán general de la isla de Cuba y ciudad de La Habana, a cargo del capitán don Esteban de Berroa. Puerto de Trinidad, 25 de agosto de 1691. AGI, Santo Domingo, 463.

57 Idem. 
Herrera, propietario de la fragata Nuestra Señora de la Concepción, 3.597 pesos y 5 reales y medio; a don Esteban de Berroa, capitán de la balandra San Pedro, 7.662 pesos y 6 reales y, por último, a Francisco de Orellón García, capitán también de la balandra San Pedro, 1.375 pesos. ${ }^{58}$ En los buceos se habían recuperado, además, 32 pedreros y 37 cámaras de bronce, que se depositaron en las Cajas Reales de La Habana. Al rey le correspondían tres cuartas partes de los 164.155 pesos y 7 reales y medio y de las piezas de artillería, esto es, 123.114 pesos y dos reales (en reales de a ocho y de a cuatro), aproximadamente, además de 24 pedreros y unas 27 cámaras de bronce..$^{59}$

Para el gobernador Manzaneda la celeridad con la que se habían ejecutado los buceos fue todo un éxito, pues tres días después de que la plata estuviera a buen resguardo arribaron al bajo de Las Víboras treinta embarcaciones inglesas procedentes de Jamaica ${ }^{60}$-isla que pertenecía a la monarquía británica desde 1655- con la firme intención de realizar el buceo en los cuatro barcos naufragados.

A pesar de la efectividad con la que parecía haberse ejecutado el buceo según Severino de Manzaneda, su precedente en el cargo, Diego Antonio de Viana, opinaba todo lo contrario, afirmando que las inmersiones se habían ejecutado de manera desordenada y fraudulenta. Entre las razones que demostraban la ineficacia anunciada por este último, cabe destacar que la plata no llegó pesada al puerto de La Habana sino a granel y que quienes la transportaron en las bestias desde Trinidad lo hicieron sin la supervisión de ningún oficial, ni del capitán general, ni de ministros, ni escribanos: «que se puso en grave peligro su transporte, porque podía haber sido robada por los piratas, negros furtivos o bandoleros». ${ }^{61}$ Según este, la intención de seguir la

58 Galeones del general marqués del Vado del Maestre. La Habana, 20 de julio de 1691. AGI, Santo Domingo, 463. La diferencia entre Esteban de Berroa y Francisco de Orellón reside en que el primero de ellos va por comandante y cabo de los tres navíos, y su elección para embarcarse en cualquiera de ellas le otorgaría poder y facultad semejantes a la de un capitán general. El segundo haría las funciones de capitán de mar y guerra.

59 Testimonio dado por José Miguel Calabrés, escribano de cámara de la Audiencia de la Contratación de Sevilla, de los autos seguidos en ella el año de 1698, en fuerza de órdenes del Consejo de Indias, para el cobro y distribución del caudal remitido de La Habana procedente del buceo de los cuatro navíos que se perdieron en el bajo de Las Víboras. Madrid, 18 de febrero de 1698. AGI, Contaduría, 394.

60 Carta del gobernador y capitán general de la isla de Cuba, don Severino de Manzaneda, informando de la llegada de treinta embarcaciones inglesas al bajo de Las Víboras. La Habana, 20 de octubre de 1691. AGI, Santo Domingo, 463.

61 Carta de don Diego Antonio de Viana, avisando al rey de los desórdenes y fraudes que se dieron en la plata que se sacó del buceo de La Víbora, de las cuatro naos del cargo del marqués del Vado del Maestre. En el castillo del Morro de La Habana, 28 de junio de 1692. AGI, Santo Domingo, 463. 
ruta que une ese lugar con La Habana —en vez de llevar la plata a Batabanó, ciudad más cercana y segura - fue la de elegir el camino más largo para lograr mayor provecho de lo obtenido en el buceo. Así, una vez terminadas las inmersiones, Severino de Manzaneda nombró por alcalde ordinario a Esteban de Berroa, prueba inequívoca de que entre todos los participantes del negocio se debían muestras de agradecimiento por lo obtenido de los cuatro barcos naufragados. ${ }^{62}$

Finalizado el buceo, tocaba emprender el viaje de vuelta a Cádiz, aunque en los navíos de la conserva de la flota y armada del general Diego de Córdoba no se transportó lo recaudado. Todavía a principios de 1698, el Consejo de Indias pedía que se enviase la hacienda dejada en La Habana en 1691 tras el buceo realizado en el bajo de Las Víboras. El dinero se emplearía en la compra de tabaco en hoja y se remitiría a España en las flotas y armadas que pasarían por el puerto habanero en $1699 .{ }^{63}$

No obstante, la situación se volvería a complicar nuevamente para el general en su viaje de regreso a Cádiz, pues, poco después de haber salido de Cuba en dirección a la metrópoli, el galeón nombrado Nuestra Señora del Mar, San José y San Francisco de Paula, de 852 toneladas, naufragó en el golfo de las Bermudas, a pesar de que había sido reparado en Cartagena antes de emprender el viaje de vuelta y era uno de los galeones más nuevos de la formación. ${ }^{64}$ Las personas que iban en él se salvaron y también buena parte de la hacienda que transportaba ${ }^{65}$ Como parte de los informes que se realizaron con motivo de este suceso, se dibujó un croquis del hundimiento del galeón, en donde se observa que varias lanchas -embarcaciones auxiliares que debía llevar cada galeón, aunque no siempre se disponía de ellas en los buques - facilitaron el rescate de la plata, la tripulación y los pasajeros (figura 2). El final del navío está muy cerca, tal y como se aprecia

62 Idem.

63 Carta del señor maestre de campo, Diego de Córdoba Lasso de la Vega, gobernador y capitán general de la ciudad de La Habana e isla de Cuba, al rey, informándole del procedimiento para la compra de tabaco en hoja. La Habana, 6 de diciembre de 1698. AGI, Santo Domingo, 463.

64 Reparaciones realizadas a los galeones y pataches de la armada desde el día 1 de mayo hasta el día 27 del mismo mes: el galeón Nuestra Señora del Mar, el galeón Nuestra Señora de las Mercedes, patache de la Margarita, el patache de la armada Nuestra Señora de la Estrella. Cartagena, 27 de mayo de 1691. AGI, Contratación, 3196. Pedro Sánchez, maestro mayor de calafate del galeón capitana, dijo lo siguiente: «era normal que entrara agua por la flaqueza y antigüedad de las carenas y que con las planchadas que se le pusieron está seguro podrá hacer viaje a España».

65 Registro de ida del navío Nuestra Señora del Mar, capitán Francisco de Pineda, que salió con la flota del marqués del Vado del Maestre para Tierra Firme. AGI, Contratación, 1248, n.1, r.2. En una nota al margen aparece citado que «este galeón se perdió viniendo de La Habana, por la mucha agua que hacía; salvose la gente y parte de la carga que traía». 
en la imagen; el agua está bastante por encima de la línea de flotación, tanto es así que las bombas ya no pueden evacuarla y el agua comienza a salir por las troneras.

Aunque la travesía que realizó el general Diego de Córdoba estuvo determinada por numerosos imprevistos, el resto de los navíos que integraban el convoy arribaron finalmente a Cádiz el 6 de noviembre de $1691 .{ }^{66}$ Atrás quedaron cinco de las embarcaciones de su conserva.



FIgURA 2. Galeón Nuestra Señora del Mar, de la flota del Marqués del Vado, naufragado en el golfo de las Bermudas en 1691. AGI, Mapas y Planos, Ingenios, 318.

\section{Conclusión}

Los diferentes siniestros que se ocasionaron en el mar durante los casi dos años que duró la empresa comandada por Diego de Córdoba, no fueron una circunstancia excepcional en la Carrera de Indias, sino más bien la tónica habitual a la que se vieron expuestas las diferentes embarcaciones que cruzaron el Atlántico, debido, entre otras cosas, a la mala reparación que se

66 Fenecimiento de cuentas. Los salarios se reciben desde el 14 de marzo de 1690 hasta el 6 de noviembre de 1691. Cádiz, 6 de noviembre de 1691. AGI, Contratación, 3195. 
hacía a los barcos y a la antigüedad de las tablas que los constituían. Desde la cuarta década del siglo XVII la Corona venía recurriendo a la concesión o merced del título de capitán de mar y guerra a quienes se comprometían a fabricar alguno de los galeones que integrarían la Armada de Tierra Firme; el carenado de tal galeón tocaría a la Real Hacienda, pero, debido a la falta de dinero de esta, fueron numerosas las ocasiones en las que el carenado corría a cuenta también de quienes lo construían - como fue el caso de Pedro Carrillo, almirante de la formación de Diego de Córdoba-, que empleaban materiales de peor calidad para la fábrica y aumentaban el coste de las carenas con el propósito de obtener mayores beneficios, reduciendo así ostensiblemente la duración de cada vaso y mermando su operatividad.

Recibido el 14 de agosto de 2017 Aceptado el 24 de octubre de 2017

\section{Referencias bibliográficas}

Castillo Mathieu, Nicolás del, «Las 18 flotas de galeones a Tierra Firme (16501700)», Suplemento de Anuario de Estudios Americanos, Sección Historiografía y Bibliografía, XLVII, 2, 1990, 83-129.

Céspedes del Castillo, Guillermo, «La avería en el comercio de Indias», Anuario de Estudios Americanos, II, Sevilla, 1945, 515-698.

Fernández Duro, Cesáreo, Armada española desde la unión de los reinos de Castilla y de Aragón, Tomo IV (1621-1652), Madrid, Est. Tipográfico «Sucesores de Rivadeneyra», 1898.

Font de Villanueva, Cecilia, «Política monetaria y política fiscal en Castilla en el siglo XVII: un siglo de inestabilidades», Revista de Historia Económica / Journal of Iberian and Latin American Economic History, 23, 1, 2005, 329-347.

Haring, Clarence H., Comercio y navegación entre España y las Indias en la época de los Habsburgo, México, Fondo de Cultura Económica, 1979.

Navarrete Peláez, María Cristina, «La granjería de las perlas del Río de la Hacha: rebelión y resistencia esclava (1570-1615)», Historia Caribe, II, 8, 2003, 35-50.

Odriozola Oyarbide, Lourdes, Construcción naval en el País Vasco, siglos XVI-XIX. Evolución y análisis comparativo, San Sebastián, Diputación Foral de Guipúzcoa, Departamento de Economía y Turismo, 2002.

Pérez-Mallaína Bueno, Pablo Emilio, Los hombres del Océano. Vida cotidiana de los tripulantes de las flotas de India, siglo XVI, Sevilla, Diputación Provincial de Sevilla, 1992. 
Pérez-Mallaína Bueno, Pablo Emilio, «Generales y almirantes de la Carrera de Indias: una investigación pendiente», Chronica nova. Revista de Historia Moderna de la Universidad de Granada, 33, Granada, 2007, 285-332.

Pérez-Mallaína Bueno, Pablo Emilio, «Juan Gutiérrez Garibay. Vida y hacienda de un general de la Carrera de Indias en la segunda mitad del siglo XVI», Revista de Indias, 70, 249, Madrid, 2010, 319-344.

Pérez-Mallaína Bueno, Pablo Emilio y Torres Ramírez, Bibiano, La Armada del Mar del Sur, Sevilla, Escuela de Estudios Hispano-Americanos, 1987.

Segovia Salas, Rodolfo, «El naufragio de la Armada de la Guardia en 1605 de la Carrera de Indias», Boletín de Historia y Antigüedades, XCIV, 836, Bogotá, 2007, 3-38.

Serrano Mangas, Fernando, Naufragios y rescates en el tráfico indiano durante el siglo XVII, Extremadura, Colección Encuentros, 1991.

Serrano Mangas, Fernando, Función y evolución del galeón en la Carrera de Indias, Madrid, Fundación Mapfre América, 1992.

Serrano Mangas, Fernando, «Realidad, ensayos y condicionamientos de la industria de construcción naval vasca durante el siglo XVII en la Carrera de Indias», Itsas Memoria. Revista de Estudios Marítimos del País Vasco, 2, Donostia-San Sebastián, 1998, 223-236.

Vila Vilar, Enriqueta, «Las ferias de Portobelo: apariencia y realidad del comercio con Indias», Anuario de Estudios Americanos, XXXIX, Sevilla, 1982, 275-340. 